\title{
The Present Situation and Countermeasure of Ad Hoc Post General Practitioners in China
}

\author{
Chuanxia Cui ${ }^{1}$, Limin Tang ${ }^{2}$ \\ ${ }^{1}$ Qiingdao University, Qingdao, China \\ ${ }^{2}$ Qingdao University Hospital, Qingdao, China \\ Email: ccxqdfy@163.com
}

How to cite this paper: Cui, C.X. and Tang, L.M. (2018) The Present Situation and Countermeasure of Ad Hoc Post General Practitioners in China. Open Access Library Journal, 5: e4241.

https://doi.org/10.4236/oalib.1104241

Received: December 10, 2017

Accepted: February 21, 2018

Published: February 24, 2018

Copyright (C) 2018 by authors and Open Access Library Inc.

This work is licensed under the Creative Commons Attribution International License (CC BY 4.0).

http://creativecommons.org/licenses/by/4.0/

cc) (7) Open Access

\begin{abstract}
Objective: To find out the existing problems and to put forward the corresponding suggestions through understanding the special training status of general practitioners in the special posts in four provinces of China. Methods: According to the general practitioners' ad hoc post planning information collection system designed by the National Planning Commission of the Ministry, our team collected data about the general practitioners of four provinces for a long time. Then the data were qualitatively described. Result: The existing problems were the difficulty of losing and recruiting the talents. The implementation of "county management of townships and townships" had not been implemented yet, the remuneration level significantly fell below the expected income and the after-service roadmap was not clear. Conclusion: In order to promote the development of general practitioner posts, it is necessary to improve the remuneration of grassroots health workers, considering the problems of county administration and rural development within the framework of talent integration, actively promoting the localization of talents and improving the training pertinence.
\end{abstract}

\section{Subject Areas}

Health Policy

\section{Keywords}

Ad Hoc Post, General Practitioner, Countermeasure

\section{Introduction}

Ad Hoc Post was the special position set for the situation that our country Midwest grassroots general practitioner was short, in the county public medical 
institutions specially set up and will be hired general practitioner stationed in township hospitals work very set up post [1]. By the end of 2013, the national health and Family Planning Commission in conjunction with the Ministry of finance, the Ministry of human resources and the State Administration of traditional Chinese medicine and the medical reform office of the State Council in accordance with the "Interim Measures" regarding the development of GPS ad hoc post pilot program, first carry out GPS ad hoc post pilot in 4 provinces Anhui, Hunan, Sichuan and Yunnan in central and western the priority of the general practitioner in remote areas difficult and no shortage of township hospital physicians problem. The development of ad hoc general practitioner team improves the talent shortage of primary health care institutions, improves township hospital medical service level and business ability, and establishes a long-term mechanism to explore the township hospitals, to attract and retain qualified personnel and make good use of talent.

\section{Current Situation and Flow Situation of Special General Practitioner}

\subsection{Present Situation}

\subsubsection{Quantity and Distribution}

According to the evaluation survey about the general practitioner special post program, at the end of June 2016, four pilot provinces, there are 962 special posts general practitioner, covering 51 cities (districts), 204 counties (cities, districts) and 816 township hospitals.

\subsubsection{Structure}

Sex structure. The total number of special post general practitioners is 1059 , of which $62.7 \%$ are males and $37.7 \%$ females.

Age structure. According to the general situation of the special post general practitioner, the average age was 37.7 years old, the majority was $34-44$ years old, accounting for $45.64 \%$; The people below 25 years old, accounting for $0.96 \%$; 60 years old and above $3.30 \%$. Of all general practitioners, the youngest was 21 years old and the oldest was 67 years old.

Educational structure. The employed special posts general practitioners in four provinces, Specialist was the most post-secondary education, accounting for $49.47 \%$, followed by undergraduate, $33.90 \%$, secondary $15.57 \%$, master and above $1.06 \%$. Details were showed in Table 1.

Title structure. The primary title of special post is $61.29 \%$. Among them, Anhui is mainly based on intermediate titles, Hunan and Yunnan are mainly junior titles, and all of them were junior and intermediate titles in Sichuan Province, and the proportion is not big. Details were showed in Table 2.

\subsection{Salary and Establishment Management}

Special post doctor expects revenue. Investigation shows, special post GPS expected a monthly income was 6373.9 yuan, more than the actual income 
Table 1. Educational background distribution (\%).

\begin{tabular}{ccccc}
\hline Province & $\begin{array}{c}\text { Graduate } \\
\text { student }\end{array}$ & $\begin{array}{c}\text { Undergraduate } \\
\text { college }\end{array}$ & $\begin{array}{c}\text { Junior } \\
\text { College }\end{array}$ & $\begin{array}{c}\text { Secondary } \\
\text { specialized school }\end{array}$ \\
\hline Anhui & 3.77 & 65.09 & 26.42 & 4.72 \\
Hunan & 0 & 34.15 & 65.85 & 0 \\
Sichuan & 0 & 21.43 & 77.86 & 0.71 \\
Yunnan & 0.47 & 22.43 & 45.33 & 31.78 \\
Total & 1.06 & 33.90 & 49.47 & 15.57 \\
\hline
\end{tabular}

Table 2. Title distribution (\%).

\begin{tabular}{cccccc}
\hline Province & Senior Title & $\begin{array}{c}\text { Deputy } \\
\text { senior }\end{array}$ & intermediate & primary & No title \\
\hline Anhui & 0 & 8.26 & 78.51 & 13.22 & 0 \\
Hunan & 0 & 0 & 5.21 & 93.75 & 1.04 \\
Sichuan & 0 & 0 & 48.44 & 51.56 & 0 \\
Yunnan & 0.72 & 5.05 & 19.86 & 73.29 & 1.08 \\
Total & 0.36 & 4.30 & 33.33 & 61.29 & 0.72 \\
\hline
\end{tabular}

49.4\%. Details were showed in Table 3.

For special general practitioners, the compilation is an important factor for attracting special general practitioners. However, a special post GPS into the organization management, $7.9 \%$ ( 14 counties) of the county special post GPS hired after the braiding; $43.3 \%$ (77 counties) of the county, said the end of the examination is included; $33.2 \%$ (59 counties) referred the county did not have explicitly file.

\subsection{Outflow}

As of June 2016, there were 962 general practitioners in the post office, a decrease of $97(9.2 \%)$ compared with 2014. During the trial, four provinces a total outflow of 149 people, the outflow rate of $14.1 \%$.

\section{Problems}

\subsection{Coexistence of Talents Recruitment Difficulties and Outflow Seriously}

In September, 2014, there were 1059 general practitioners of special post in position, which failed to complete the tasks of recruiting 1080 doctors of special post issued by state. In order to alleviate the shortage of talents at the grassroots, Yunnan province and other places have been lowered to the assistant practicing doctors in accordance with local conditions. By the end of August, 2016, there were a total of 149 outflow of general practitioners of special post, the outflow rate reached by $14.1 \%$, although a total of 52 was filled the gap from other places, there was still a large net loss rate. On the one hand, it was difficult to recruit 
Table 3. Income survey of special general practitioners (yuan).

\begin{tabular}{ccc}
\hline Province & Monthly average wage & Expected wage \\
\hline Anhui & 4274.7 & 6285.7 \\
Hunan & 3987.7 & 5800.9 \\
Sichuan & 4361.2 & 6767.0 \\
Yunnan & 4340.1 & 6508.1 \\
Total & 4267.1 & 6373.9 \\
\hline
\end{tabular}

talents, on the other hand, the loss of talents was serious, which was coexisted and resulted instability in the team of general practitioners of special post.

\subsection{The Strategy of "County Management and Rural Use" Was Not Implemented}

The strategy of "county management and rural use" was a breakthrough for the plan of general practitioners of special post, which not only enhanced the job attractiveness, but also fully played the support role of county-level medical institutions, further improved the technical level of general practitioners of special posts, and enhanced the service capacity of grassroots medical and health institutions, however, the survey found that the county hospital did not play an important role, and only $28.6 \%$ of the special post doctors in the county signed contracts with county medical institutions.

\subsection{Salary Level Was Significantly Lower than Expected}

The expected salary of general practitioners of special posts was 6373.9 yuan every month, which exceeded the actual income by $49.4 \%$. The salary level was lower than expected, which was the epitome of lower income level of grassroots health workers, if increasing their incomes, it will seriously affect the enthusiasm of other staff. In addition, the main reason for the departure of general practitioners of special post during the term was dissatisfaction with their related benefits.

\subsection{The Way after the Expiration of the Service Was Unclear}

The establishment was an important factor affecting the attractiveness of general practitioners of special post and solving the problem of introducing and retaining talents. However, there was no clear indication for bringing the general practitioners of special post into the management of the establishment in all pilot areas, which led to staff of special post concerning and worrying about settlement after expiration of service.

\section{Suggestions}

\subsection{Improving the Remuneration of Grassroots Health Workers}

To solve this problem, we should not simply increase the income of general practitioners of special post, otherwise it will seriously affect the enthusiasm of 
other staff. It is necessary to start from the source and plan and consider as a whole. Firstly we should improve the remuneration of grassroots health workers. In accordance with relevant state policies, the balance of payments for the grassroots medical and health institutions can be used for personnel rewards, we can explore the form of paid contract service and collect appropriate fees, the allowances of state policy for working in hard and remote areas and subsidies for working in grassroots has not been put into practice in many places, which are effective measures to improve the enthusiasm of grassroots health workers. In addition, local governments can set up allowance for grassroots medical staff according to local conditions, differential subsidies [2] can be provided according to different levels divided by hard and remote degrees. The remuneration of grassroots health talents has been improved, so the number of general practitioners of special post will be higher in the future.

\subsection{Considering the Problems of County Management, Rural Use and Establishment in the Framework of Talent Integration}

The county hospital did not play an important role in the plan of general practitioners of special post, the main reason was the lackness of motivation, the county hospital can not gain interests but need to bear the additional responsibility of management and assistance. County health and Family Planning Administrative Departments can actively promote the pilot of integrated cooperation forms, such as establishing close health alliance and medical groups to realize the community of responsibility and interests between township health centers and county-level medical institutions. The service mode of coordinated development of county and town integration allows general practitioners of special post to improve their own quality and meets their personal development needs by means of further study at county hospitals, participation in remote consultation and online learning. At the same time, for the situation that the establishment of special post staff was still difficult to implement in some places, it is recommended to consider and unified resolve at the county reform of public hospitals in the framework of county and town integration. It is suggested to establish county health human resource management, arrange health personnel for work shift in county and town according to the need, develop standard for work shift and share rural health human resource [3].

\subsection{Actively Promote the Localization of Talents}

Localization of talents is an important factor in recruiting and retaining talents. All localities should increase propaganda and promote the localization of talents, and actively attract general practitioners, practicing (assistants), physicians to practice in their hometowns, which to a certain degree, improves the stability of the general practitioners of special post. In addition, the dispatch of some local general practitioners of special post can follow the principle of "team dispatch" and "nearby dispatch", which can enhance mutual support between special post doctors, let themselves adapt the new environment, which was conducive to the 
stability of staff.

\subsection{Improving Pertinence of Training}

Training and learning, as a matter of great concern to the special postdoctor, which was related to the improvement of individual ability and long-term development [4]. At the same time, the pilot township hospitals should also carry out appropriate technical outpatient service based on the actual needs of local people. Therefore, the help of county agency for general practitioners of special post, the organization of superior agency and the participation of special post doctor in various training should start from the local needs, training or learning appropriate technology according to the actual conditions of health centers. So, we can improve the level of technology and service capabilities with pertinence, as to serve local people well.

\section{References}

[1] Zhao, M.Y., Chen, W.J., et al. (2015) Application of Module Teaching in Special post Training for General Practitioners. Chinese Health Professionals, 12, 50-53.

[2] Du, H.F. and Ji, D.W. (2008) Countermeasures to Solve the Problem of Lack of Rural Health Professionals. Frontier, 3, 129.

[3] Cai, H.Z. (2010) Study on the Human Resources of Township Hospitals under the New Rural Cooperative Medical System. Chinese Journal of Social Medicine, 27, 23-25.

[4] Xiao, C.Y. and Cheng, X.M. (2003) General Practitioner Team Construction and General Medical Education Status Analysis. Chinese General Medicine, 6, 642-644. 